\title{
Purple-fleshed sweet potato genotypes as the ingredients for crisps and noodle making
}

\author{
Erliana Ginting *, Joko Susilo Utomo, and Joko Restuono \\ Indonesian Legumes and Tuber Crops Research Institute (ILETRI), Jalan Raya Kendalpayak Km 8 \\ Malang, East Java 65101, Indonesia
}

\begin{abstract}
The presence of anthocyanins in purple-fleshed sweet potato has been intensively promoted as functional foods regarding its high antioxidant activity and essential health benefits. Therefore, a number of attractive and nutritious food products needs to be developed in order to diversify the utilization and increase the consumption. As selected promising purple-flesh sweet potato genotypes have been available, their suitability prepared for different food products needs to be studied. About 12 genotypes of sweet potato with varied purple color intensity or deepness were processed into crispy chips (crisps) and noodles and evaluated their physical properties (yield, lightness, hardness) and sensorial attributes (color, aroma, texture, taste) using a Hedonic test with 20 panelists. The results showed that sweet potato genotypes with purple flesh in combination with yellow/orange or white color, namely MSU 06046-74, Antin 1, and MSU 06044-05 were suitable for crisps making, followed by those with medium purple color, such as Aya Murasaki, MIS 0612-73, MIS 0614-02, MIS 0601-22, and MSU 06014-51. Conversely, sweet potato with deep purple color, namely MSU 06028-71 and MSU 06046-48 were tailored for the ingredients of noodles. This information would be useful for releasing new purple sweet potato varieties in addition to their excellent agronomic traits.
\end{abstract}

\section{Introduction}

Sweet potato is a rich source of carbohydrate, vitamin, mineral and dietary fiber as well as bioactive components, such as beta carotene, anthocyanins, and phenolic compounds that are beneficial for human health [1]. Anthocyanins that are particularly present in the purplefleshed sweet potato have been intensively studied regarding their high antioxidant capacities and physiological properties, such as hepato-protective, antimutagenic, antihypertensive, antihyperglycemic, antimicrobial, and anti-inflammatory [2-6]. Antioxidative activities may also prevent degenerative diseases related to free radicals, such as cancer, atherosclerosis, aging, diabetes, and arthritis. The high content of anthocyanins in purple-fleshed sweet potato is also essential in their applications as natural food colorants due to higher stability to heating and UV irradiation than those of anthocyanins derived from strawberry, raspberry, apple dan black soybean [3-7].

\footnotetext{
* Corresponding author: erlianaginting@yahoo.com
} 
The predominant use of sweet potato in Indonesia is for food that accounts about $89 \%$ of the production with a consumption level of $7.9 \mathrm{~kg} / \mathrm{capita} /$ year [8]. However, most of traditional sweet potato food products are assumed to be less attractive relative to those derived from wheat flour. Therefore, a number of food products need to be developed and introduced to both the processors and consumers. Sweet potato can be potentially used as a partly substitute of wheat flour in many products, such as bakery, noodles, and snacks. A well-known deep-fried products like crispy chips can be also produced from sweet potato as prepared from potato, cassava and other tubers [9]. Promotion of health benefits and the availability of a variety of alternative food products from sweet potato would help to increase the consumption as well as the health status of the community and support the local food diversification program.

Currently, selected of high yielding sweet potato genotypes or clones ( $>35 \mathrm{t} / \mathrm{ha}$ ) with different purple color intensity are available as a result of series of breeding activity. Prior to be released as new varieties, these genotypes need to be evaluated to determine their suitability for food products in order to be accepted by users. Previously, three purple-fleshed sweet potato varieties have been released, namely Antin 1 (white purplish), Antin 2 (red purple) and Antin 3 (deep purple) [10]. In this study, selected promising purple-fleshed sweet potato genotypes were used as ingredients for crispy chips (crisps) and noodle making and evaluated the suitability of their physical and sensorial attributes. Sweet potato mash could substitute $31-40 \%$ of wheat flour in noodle preparation $[11,12,13]$. About 10.7 million tons of wheat grain was imported in 2019 [14] and the major use of wheat flour (55\%) is for making wet and dry noodles [15]. Expectedly, suitable promising genotypes for ingredients of crisps and noodles can be come up through this study in terms of enhancing their adoption by farmers and utilization by food processors.

\section{Materials and methods}

Ten purple-fleshed sweet potato promising genotypes or clones, namely MSU 06014-51, MSU 06028-71, MSU 06044-05, MSU 06046-48, MSU 06046-74, MIS 0601-22, MIS 0601179, MIS 0612-73, MIS 0614-02, MIS 0656-220 and two varieties (Aya Murasaki and Antin 1) as checks were harvested after 4-4.5-month planting in Tumpang, Malang. Antin 1 variety was the first purple-fleshed sweet potato released in Indonesia in 2013 with a white purplish flesh [10], while Aya Murasaki is an introduction variety from Japan, which has a deep purple flesh and is widely cultivated in Malang area, East Java [16]. The fresh tubers were observed for their flesh colors visually and the Hunter colors $\left(\mathrm{L}^{*}, \mathrm{a}^{*}, \mathrm{~b}^{*}\right)$ using a color reader of Minolta CR-200b in the Food Chemistry Laboratory of Indonesian Legumes and Tuber Crops Research Institute (Iletri), Malang. The chemical composition and anthocyanin contents were also analyzed and have been published previously [17].

The fresh tubers were peeled, washed and sliced using a manual chipper with $2-3 \mathrm{~mm}$ of thickness, soaked in salt and sodium bicarbonate solution for $10 \mathrm{~min}(0.025 \% \mathrm{~b} / \mathrm{v}$ and $0.005 \% \mathrm{~b} / \mathrm{v}$, respectively), then deep-fried using a vacuum fryer $\left(130^{\circ} \mathrm{C}, 10 \mathrm{~min}\right)$, and spined to remove the excessive oil to obtain the crisps. This optimal condition was obtained as a result of trial and error during this study. The fresh tubers were also washed, steamed for 30 min, peeled and mashed then processed into dry noodles. Firstly, the sweet potato mash was blended with wheat flour and cassava starch with the proportion of $40 \%, 50 \%$ and $10 \%$ and added with small amounts of salt and egg liquid, then molded into noodles using a manual noodle making, steamed for 3 min and oven-dried for $4 \mathrm{~h}$ following the preparation method used by [11]. A randomized complete design was applied for the trial with three replicates. Observations were performed for the physical (yield recovery, lightness/L* and hardness level using a texture profile analyzer) and sensorial attributes (color, aroma, texture/crispness, 
and taste) using a Hedonic test with 20 panelists. Data was analyzed using ANOVA and followed by an LSD test at 5\% level to obtain the differences between genotypes.

\section{Results and discussion}

\subsection{The fresh tuber colors}

The 12 genotypes showed different flesh colors that ranged from purple to deep purple, and white purplish to light yellow purplish (Table 1). This color was considerably dictated by the anthocyanin components that consist of blue, red and purple colors. The proportion of peonidin and cyanidin as the predominant anthocyanins in purple sweet potato may contribute to the flesh color. The red-purple color would exist if the proportion of peonidin $>1$, while purple-blue or grey color is observed if cyanidin is the major component [3-18]. Carotenoids, particularly beta-carotene may be also present in the tuber flesh with yellow and purple colors combination [19], such as seen in MSU 06044-05 genotype.

The highest lightness ( $\mathrm{L}^{*}$ ) value was noted in MSU 06044-05 and MSU 06046-74 genotypes (Table 1), which had light yellow purplish flesh and even lighter than Antin 1 (white purplish). Meanwhile, MSU 06028-71 and MSU 06014-51showed the smallest L* values, suggesting the deepest purple color. The $\mathrm{L}^{*}$ values of both genotypes were slightly higher (less purple) than those of Antin 3 and RIS 10043-02 genotypes (35.57 and 36.70, respectively) as reported by [20]. Three purple genotypes originated from North Carolina; USA even had deeper color with $\mathrm{L}^{*}$ values ranged from 15.3 to 19.4 [21]. The $\mathrm{L}^{*}$ value was negatively correlated with the anthocyanin content $[17,20]$, suggesting that the lower the $\mathrm{L}^{*}$ value, the darker or deeper purple color of the flesh (Table 1) and the higher content of anthocyanins. The anthocyanin contents ranged from $4.29 \mathrm{mg}$ to $123.92 \mathrm{mg} / 100 \mathrm{~g}$ (equivalent to cyanidin 3-glycoside) with highest value noted in MSU 06046-48 and the lowest value in MSU 06046-74 as previously reported by [17]. Deep-purple genotypes are preferred for flour ingredient and natural colorant, while for snacks, noodles, juice, and jam preparation, the redpurple genotypes are desired [16]. Purplish flesh color is tailored for making crisps, such as Antin 1 which is particularly released for such purpose [10].

The highest redness ( $\mathrm{a}^{*}$ ) value was noted in MIS 0612-73 and MIS 0601-22, while it was seen in MSU 06046-74 for the yellowness value ( $b^{*}$ ), followed by MSU 06044-05 (Table 1). The latter two genotypes had yellow purplish color; thus, it was in agreement with their high $\mathrm{b}^{*}$ values. The redness $\left(\mathrm{a}^{*}\right)$ showed no correlation with $\mathrm{L}^{*}$ value, while the yellowness $\left(\mathrm{b}^{*}\right)$ had a positive correlation $\left(R^{2}=0.95\right)$, suggesting that the yellow color contributes more to $\mathrm{L}^{*}$ value relative to the red color, particularly for those tuber flesh having a purple combination with yellow and white colors. 
Table 1. The flesh colors of 12 purple sweet potato genotypes

\begin{tabular}{clccc}
\hline Genotype & \multicolumn{4}{c}{ Color } \\
\cline { 2 - 5 } & Visual observation & L $^{*}$ & $\mathbf{a}^{*}$ & $\mathbf{b}^{*}$ \\
\hline MSU 06014-51 & Purple ++++ & $37.37 \mathrm{~h}$ & $29.30 \mathrm{fg}$ & $8.64 \mathrm{~h}$ \\
MSU 06028-71 & Purple ++++ & $37.10 \mathrm{~h}$ & $30.27 \mathrm{ef}$ & $11.23 \mathrm{~g}$ \\
MSU 06044-05 & Light yellow purplish & $77.07 \mathrm{a}$ & $26.93 \mathrm{~h}$ & $38.80 \mathrm{~b}$ \\
MSU 06046-48 & Purple ++++ & $38.57 \mathrm{~g}$ & $31.03 \mathrm{def}$ & $11.60 \mathrm{fg}$ \\
MSU 06046-74 & Light yellow purplish & $77.47 \mathrm{a}$ & $27.17 \mathrm{gh}$ & $41.53 \mathrm{a}$ \\
MIS 0601-22 & Purple ++ & $54.80 \mathrm{c}$ & $40.80 \mathrm{a}$ & $18.87 \mathrm{~d}$ \\
MIS 0601-179 & Purple +++ & $44.30 \mathrm{ef}$ & $32.53 \mathrm{de}$ & $13.43 \mathrm{f}$ \\
MIS 0612-73 & Purple ++ & $50.57 \mathrm{~d}$ & $40.77 \mathrm{a}$ & $15.77 \mathrm{e}$ \\
MIS 0614-02 & Purple +++ & $44.57 \mathrm{e}$ & $35.80 \mathrm{~b}$ & $11.83 \mathrm{fg}$ \\
MIS 0656-220 & Purple +++ & $43.27 \mathrm{f}$ & $37.07 \mathrm{~b}$ & $12.80 \mathrm{fg}$ \\
Ayamurasaki & Purple +++ & $43.27 \mathrm{f}$ & $35.00 \mathrm{bc}$ & $11.70 \mathrm{fg}$ \\
Antin-1 & White purplish & $63.73 \mathrm{~b}$ & $33.20 \mathrm{~cd}$ & $23.37 \mathrm{c}$ \\
\hline
\end{tabular}

Values in the same column followed by the same letters are not significantly different $(P<0.05)$

$\mathrm{L}^{*}$ : lightness level that ranges from 0 (dark/black) to 100 (light/white)

$a^{*}$ : Redness level that ranges from green $(-100)$ up to red $(+100)$

$\mathrm{b}^{*}$ : Yellowness level that ranges from blue $(-100)$ up to yellow $(+100)$

$+\quad=$ deeper purple color

\subsection{The physical and sensorial attributes of crisps}

The lightness levels $\left(\mathrm{L}^{*}\right)$ of the crisps were significantly influenced by the sweet potato genotypes (Table 2). The crisps prepared from four genotypes showed the lowest $\mathrm{L}^{*}$ value (deep purple colors), namely MSU 06046-48, MSU 06028-71, MIS 0601-179, and Aya Murasaki. Meanwhile, the crisps processed from MSU 06046-74 (light yellow purplish) showed the highest lightness value, followed by MSU 06044-05, which had the same value as Antin 1. This reflects that the color of the crisps produced was considerably dictated by the flesh color intensity of respective genotype. In addition, the $L^{*}$ value may also be affected by the use of a vacuum fryer in this study that applied at a lower temperature and shorter time $\left(130^{\circ} \mathrm{C}, 10 \mathrm{~min}\right)$ relative to a common deep-frying $\left(145-150^{\circ} \mathrm{C}, 30 \mathrm{~min}\right)[22]$, thus degradation of the natural color of the tuber flesh can be minimized.

The hardness levels of the crisps were also significantly different between the sweet potato genotypes (Table 2) with the highest value (firm) seen in MIS 0601-179, where MIS 0612-73 and MIS 0614-02 gave the lowest value (crispy), followed by Antin 1. Five sweet potato clones seemed to have the same hardness levels with those made from Aya Murasaki, namely MSU 06028-71, MSU 06044-05, MSU 06046-48, MIS 0601-22, and MIS 0656-220. Aya Murasaki is an introduction variety from Japan [16] and is commonly used as an ingredient for crisps. The thickness of the slice may also affect the hardness or crispness of the crisps. The slice of 1-2 mm thickness as also used in study was reported to give good crispness [22].

MIS 0601-179 genotype showed the highest yield recovery of crisps, however it was not significantly different with MSU 06044-05, MSU 06014-51, and MSU 06028-71, while MIS 0612-73 gave the lowest value (Table 2). As the frying method used was similar, the differences in crisps yield might due to the initial moisture content of the fresh tubers. High tuber moisture content like noted in MIS $0612-73$ c.a. $75.9 \%$ [17], would considerably decrease the weight or yield of the crisps after deep-frying relative to MIS 0601-179, which had the lowest moisture content $(60.1 \%)$ as the water loss will be replaced by the oil uptake (23). 
Table 2. Lightness, hardness, and yield recovery of crisps prepared from 12 purple-fleshed sweet potato genotypes

\begin{tabular}{cccc}
\hline Genotype & Lightness $\left(\mathbf{L}^{*}\right)$ & Hardness $(\mathbf{N})$ & Yield recovery (\%) \\
\hline MSU 06014-51 & $35.87 \mathrm{~cd}$ & $15.2 \mathrm{~b}$ & $40.26 \mathrm{abc}$ \\
MSU 06028-71 & $34.27 \mathrm{e}$ & $10.8 \mathrm{de}$ & $39.46 \mathrm{abc}$ \\
MSU 06044-05 & $53.2 \mathrm{~b}$ & $10.8 \mathrm{de}$ & $40.95 \mathrm{ab}$ \\
MSU 06046-48 & $34.07 \mathrm{e}$ & $11.1 \mathrm{de}$ & $38.60 \mathrm{bcd}$ \\
MSU 06046-74 & $62.73 \mathrm{a}$ & $13.5 \mathrm{c}$ & $37.63 \mathrm{bcd}$ \\
MIS 0601-22 & $36.60 \mathrm{c}$ & $10.5 \mathrm{e}$ & $33.83 \mathrm{de}$ \\
MIS 0601-179 & $34.40 \mathrm{e}$ & $19.7 \mathrm{a}$ & $43.57 \mathrm{a}$ \\
MIS 0612-73 & $36.30 \mathrm{c}$ & $6.9 \mathrm{~g}$ & $30.00 \mathrm{e}$ \\
MIS 0614-02 & $36.83 \mathrm{c}$ & $7.8 \mathrm{fg}$ & $35.95 \mathrm{~cd}$ \\
MIS 0656-220 & $35.93 \mathrm{~cd}$ & $11.9 \mathrm{~d}$ & $36.97 \mathrm{bcd}$ \\
Ayamurasaki & $35.00 \mathrm{de}$ & $10.9 \mathrm{de}$ & $38.24 \mathrm{bcd}$ \\
Antin-1 & $53.53 \mathrm{~b}$ & $8.6 \mathrm{f}$ & $38.48 \mathrm{bcd}$ \\
\hline Values in the same column followed by the same letters are not significantly different $(P<0.05)$
\end{tabular}

Values in the same column followed by the same letters are not significantly different $(P<0.05)$

The crisps colors prepared from MSU 06046-74 and MSU 06044-05 (light yellow purplish), Antin 1 (white purplish), MIS 0601-22, and MIS 0612-73 (purple) were fairly liked by panelists and the other six genotypes were slightly liked, including Aya Murasaki, while MIS 0601-179 was disliked (Fig. 1). This suggests that panelists tended to prefer the bright color crisps compared to dark or deep purple ones. An elevated temperature from $80^{\circ} \mathrm{C}$ to $100^{\circ} \mathrm{C}$ would consequently degrade the anthocyanins as well as the organic acids and sugars attached to anthocyanins. This resulted in changes the color into brown compounds [24] that would subsequently affect the color preference of the crisps produced. A decrease in anthocyanins up to $52.4 \%$ was reported during deep-frying for $12 \mathrm{~min}$ at $120^{\circ} \mathrm{C}$ [25]. High content of sugars in sweet potato tuber may also cause Maillard, a non-enzymatic browning reaction with amino acids during frying (23).
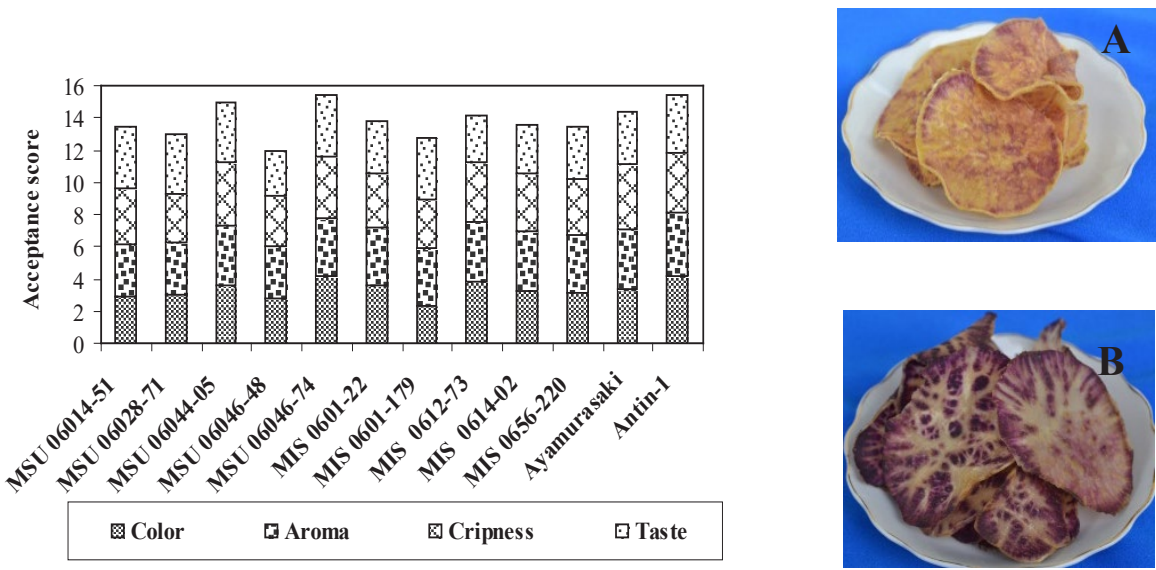

Score: 1 = Dislike very much, 2 = Dislike moderately, $3=$ Likes lightly, $4=$ Like moderately, $5=$ Like very much

Fig. 1. Sensorial attributes of the crisps made from 12 purple-fleshed sweet potatoes.
Fig. 2. Crips of MSU 06046-74 (A) and Antin 1 (B).

The aroma of the crisps derived from the nine clones, including Aya Murasaki and Antin 1 , was fairly liked by the panelists, while the remaining three clones were less preferred 
(Fig.1) that was associated with the flavor components in the fresh tubers. The texture of the crisps prepared from six genotypes was crispy, thus they were relatively liked by the panelists, including Aya Murasaki. Meanwhile the other six genotypes were slightly crispy, including Antin 1 (Fig. 1). This phenomenon was in accordance with the hardness level of the crisps, particularly for those made from MIS 0601-179, which had a greater value or firmer than that of Aya Murasaki (Table 2). Six genotypes had a favorable taste of crisps, including Antin 1, while the other six genotypes were less liked, including Aya Murasaki (Fig. 1).

Overall, the crisps processed from MSU 06046-74 was the most preferred based on the color, aroma, texture and taste attributes (Fig. 2A), followed by Antin 1 (Fig. 2B) and MSU 06044-05 (Fig. 1). This indicated that the three genotypes, which had a yellow/white purplish flesh color were suitable as ingredients for crisps making, followed by those genotypes with medium intensity of purple color, such as Aya Murasaki, MIS 0612-73, MIS 0614-02, MIS 0601-22 and MSU 06014-51. Meanwhile, genotypes with dark/deep purple color, such as MSU 06046-48 and MIS 0601-179 were less tailored for crisps ingredients, even though a vacuum fryer had been applied in this study.

\subsection{The physical and sensorial attributes of noodles}

The lightness levels $(\mathrm{L} *$ ) of dry noodles were significantly different between genotypes (Table 3) with the highest value obtained in MSU 06044-05, while MSU 06014-51 had the lowest value (dark). The lightness level of the flesh tuber showed a positive correlation with the lightness level of the dry noodles produced with a value of $\mathrm{R}^{2}=0.89$ (Fig. 3). The noodles made from MIS 0601-179, MSU 06028-71, and MSU 06028-71 genotypes had the same lightness level as Aya Murasaki, while one noodle was darker (MSU 06014-51) and four others had brighter purple colors. Both genotypes of MSU 06044-05 and MSU 06046-74, which had light yellow purplish flesh colors produced brighter or lighter dry noodles compared to that of Antin 1 (white purple combination).

The yield recovery of dry noodles was significantly influenced by sweet potato genotypes. Two purple genotypes, namely MIS 0601-22and MSU 06046-48 gave the highest yield recovery of dry noodles that ranged from $78.03 \%$ to $78.81 \%$ (Table 3 ), while Aya Murasaki had the lowest yield (71.40\%) and the rest genotypes were in between the two groups. These differences may be attributed to the initial moisture content of the fresh tubers and water absorption of the flesh during steaming as the oven-drying time was the same. Noodles made from a blended of sweet potato mash and wheat flour approximately had 1.5fold yield recovery relative to that of $100 \%$ wheat flour [11-12], suggesting more economic beneficial of producing this noodle in addition to reducing the use of imported wheat flour.

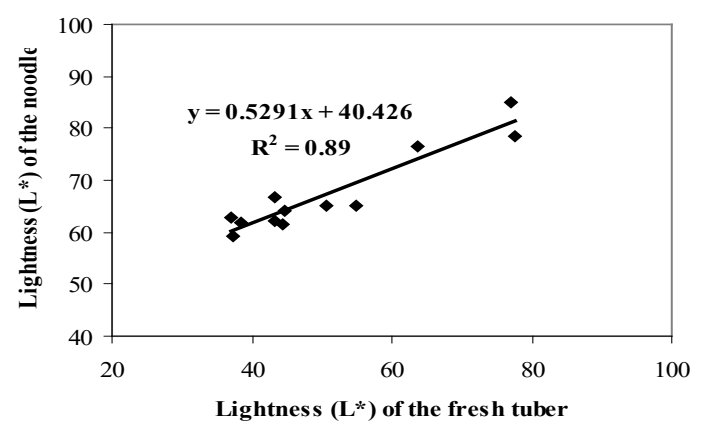

Fig 3. Relationship between the flesh and noodle lightness ( $\left.L^{*}\right)$ of 12 purple-fleshed sweet potatoes. 
Table 3. Lightness and yield recovery of noodles prepared from 12 purple-fleshed sweet potato genotypes

\begin{tabular}{ccc}
\hline Genotype & Lightness $\left(\mathbf{L}^{*}\right)$ & Yield recovery (\%) \\
\hline MSU 06014-51 & $59.30 \mathrm{~h}$ & $76.05 \mathrm{~cd}$ \\
MSU 06028-71 & $62.73 \mathrm{f}$ & $75.80 \mathrm{~d}$ \\
MSU 06044-05 & $85.07 \mathrm{a}$ & $73.59 \mathrm{ef}$ \\
MSU 06046-48 & $61.90 \mathrm{fg}$ & $78.03 \mathrm{ab}$ \\
MSU 06046-74 & $78.63 \mathrm{~b}$ & $74.44 \mathrm{e}$ \\
MIS 0601-22 & $65.07 \mathrm{e}$ & $78.81 \mathrm{a}$ \\
MIS 0601-179 & $61.40 \mathrm{~g}$ & $77.03 \mathrm{bc}$ \\
MIS 0612-73 & $65.03 \mathrm{e}$ & $72.80 \mathrm{f}$ \\
MIS 0614-02 & $64.27 \mathrm{e}$ & $77.00 \mathrm{bc}$ \\
MIS 0656-220 & $66.83 \mathrm{~d}$ & $74.53 \mathrm{e}$ \\
Aya Murasaki & $62.20 \mathrm{fg}$ & $71.40 \mathrm{~g}$ \\
Antin-1 & $76.53 \mathrm{c}$ & $77.30 \mathrm{~b}$ \\
\hline
\end{tabular}

Values in the same column followed by the same letters are not significantly different $(P<0.05)$

The panelist preference scores for the color of the dry noodles ranged from slightly liked to fairly or moderately liked (Fig.4). There were six genotypes which had scores relatively the same as Aya Murasaki (liked), while four genotypes were slightly liked, including Antin 1. In contrast to crisps which desired bright flesh color for the raw material, it seems that sweet potato with dark/deep purple flesh was preferable for noodles making as the color was more attractive. The similar color scores (fairly liked) were also previously reported by [11] for both noodles made from $100 \%$ wheat flour and blended of $50 \%$ wheat flour with $40 \%$ of purple sweet potato paste. The aroma of dry noodles made from 10 sweet potato genotypes were quite favorable, while the aroma derived from MIS 0601-22 and MIS 0601-179 noodles were less disliked that may relate to the presence of volatile compounds in the steamed tubers [26].
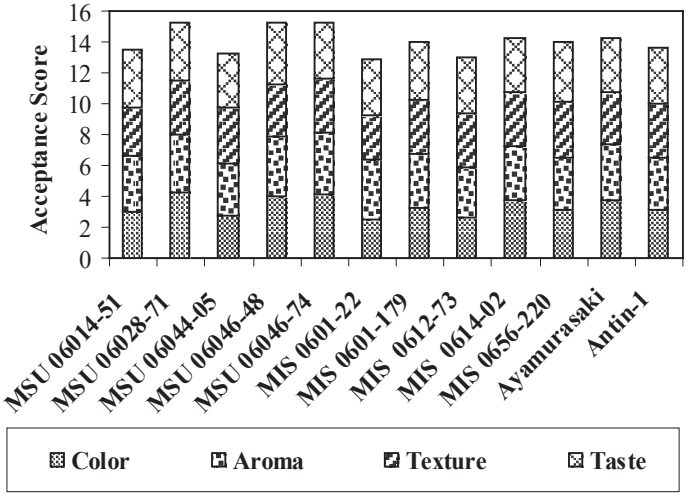

Score: $1=$ Dislike very much, 2 = Dislike moderately, 3 = Like slightly, $4=$ Like moderately, $5=$ Like very much

Fig. 4. Sensorial attributes of the noodles made from 12 purple-fleshed sweet potatoes.
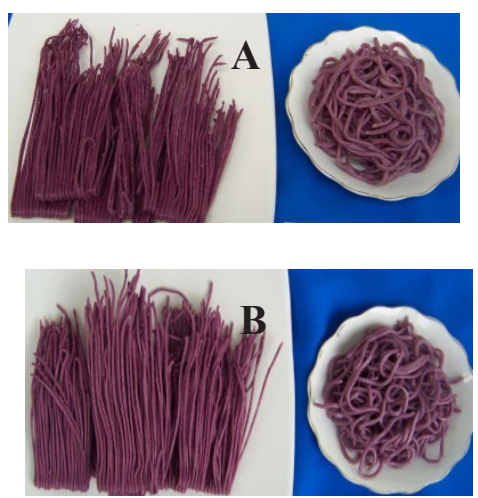

Fig. 5. Noodleof MSU 06028-71 (A) and MSU 06046-48(B).

The color of wet noodles has a slightly different preference from that of the dry noodles since there was a change in intensity of the purple color due to boiling process. It is known that anthocyanins belonged to purple sweet potato are water-soluble and sensitive to $\mathrm{pH}$ changes and heating treatment [27-28]. Panelists liked the colors of the wet noodles prepared 
from MSU 06028-71, MSU 06046-48, MSU 06046-74, MIS 0614-02, and Aya Murasaki, while the rest of five genotypes were less preferred, including Antin 1 (Table 7). Seven genotypes produced wet noodles with a fairly liked aroma, including Aya Murasaki, while the other five genotypes were less favored, including Antin 1 (Table 7). The wet noodles made from ten genotypes had a chewy texture, including Antin 1, thus they were liked by panelists, while the other two clones, including Aya Murasaki were less preferred their texture. The taste of all wet noodles derived from 12 genotypes were fairly liked by the panelists. Purple sweet potato also contained phenolic compounds in addition to anthocyanins that may give bitter and astringent mouth feel [20-29], particularly when consumed as a boiled or steamed tuber. However, such taste seemed to be less detected in the noodles produced as the sweet potato mash proportion used was only $40 \%$ and the other blends were wheat flour and tapioca $(60 \%)$. Ref. [11] even revealed that the taste of noodles made from such blends was more preferred (like) than that of derived from $100 \%$ of wheat flour (slightly like). Therefore, at present study the noodle made from $100 \%$ of wheat flour was no longer used as a control.

Over all, both the dry and wet noodles prepared from MSU 06028-71 genotype (dark/deep purple flesh) was fairly liked based on its color, aroma, texture, and taste (Fig. 5A). This was followed by MSU 06046-48 (deep purple) (Fig. 5B) and MSU 06046-74 (yellow purplish), three genotypes that had similar scores (MSU 06028-71, MIS 0614-02, and Aya Murasaki), three genotypes with the same scores (MSU 06044-05, MIS 0601-179, and MIS 0656-220), MIS 0601-22 and Antin 1 group and finally MIS 0612-73, which showed the lowest score, particularly for the color attribute. The noodles made from MSU 06046-74 genotype with a light-yellow purplish flesh color was also preferred because the color was likely similar to ordinary noodle made from $100 \%$ of wheat flour. This study reflects that there were three and nine genotypes, respectively, which had better noodles sensorial attributes compared to those prepared from Aya Murasaki and Antin 1 as variety checks. In another study, MSU 03028-10, a purple-fleshed genotype (released as Antin 2 variety in 2014) was also reported to be tailored for noodles ingredient [11]. The use of suitable purple sweet potato genotypes is promising to substitute the use of $40 \%$ wheat flour in making noodles.

\section{Conclusions}

Purple-fleshed sweet potato genotypes are promising to be used as ingredients for both crisps and noodles making. The genotypes with yellow purplish or white purplish flesh color, namely MSU 06046-74, Antin 1, and MSU 06044-05 were suitable for crips making, followed by those with medium purple color, such as Aya Murasaki, MIS 0612-73, MIS 0614-02, MIS 0601-22, and MSU 06014-51. On the other hand, sweet potato with deep purple color, namely MSU 06028-71 and MSU 06046-48 were tailored for the ingredients of noodle. This information needs to be taken into account by the breeder in releasing new purple sweet potato varieties in addition to their excellent agronomic traits.

\section{References}

1. R. Mohanraj, S.Sivasankar, J. Med. Food 17,7 (2014)

2. J.G. Zhao, Q.Q. Yan, L.Z. Lu, Y.Q. Zhang, Nutr. Res. Prac. 7,1 (2013)

3. E.C. Montilla, S. Hillebrand, P.Winterhalter, Fruit, Veg. Cereal Sci.Biotechnol. 5, 2 (2011)

4. Y.M. Lee, J.H. Bae, J.B. Kim, S.Y. Kim, M.N. Chung, M.Y. Park, J.S. Ko, J. Song, J.H. Kim, Korean J. Nutr. 45,12 (2012)

5. H. Ji, H. Zhang, H. Li, Y. Li, Food Nutr.Sci. 6,1(2015) 
6. L. Wang, Y. Zhao, Q. Zhou, C.L. Luo, A.P. Deng, Z.C. Zhang, J.L. Zhang, J. Food Drug Anal. 25, 3 (2017)

7. J. Li, X.D. Li, Y. Zhang, Z.D. Zheng, Z.Y. Qu, M. Liu, C.H. Zhu, S. Liu, M. Wang, L. Qu, Food Chem. 136, 3-4 (2013)

8. R. Suryani, Outlook Komoditas Pertanian Tanaman Pangan Ubijalar (Pusat Data dan Sistem Informasi Pertanian Kementerian Pertanian, Jakarta, 2016)

9. E. Ginting, R. Yulifianti, M. Jusuf, J. Pangan 23, 2 (2014)

10. Balitkabi, Deskripsi Varietas Unggul Kacang-kacangan dan Umbi-umbian (Balai Penelitian Tanaman Aneka Kacang dan Umbi, Malang, 2016)

11. J.S. Utomo, R. Yulifianti, Karakteristik mie berbahan baku terigu lokal dan ubijalar $u n g u$, in Proceeding Seminar Hasil PenelitianTanaman Aneka Kacang dan Umbi, 15 November 2011, Malang, Indonesia (2012)

12. E. Ginting, R. Yulifianti, Proc. Food Sci. 3, 289 (2015)

13. S. Sumartini, T.Gozali, Pasundan Food Technol. J. 4, 3 (2017)

14. BPS, Statistik Indonesia (Badan Pusat Statistik, Jakarta, 2020)

15. S. Gafar, J. Pangan 18, 4 (2009)

16. E. Ginting, J.S. Utomo, R. Yulifianti, M. Jusuf, Iptek Tan. Pangan 6, 116 (2011)

17. E. Ginting, R. Yulifianti, M. Jusuf, M.J. Mejaya, J. Penel. Pert. Tan. Pangan 34, 69 (2015)

18. J. Xu, X. Su, S. Lim, J. Griffin, E. Carey, B. Katz, J. Tomich, J.S. Smith, W. Wang, Food Chem. 186, 90 (2015)

19. S.N. Islam, T. Nusrat, P. Begum, M. Ahsan, Food Chem. 199, 628 (2016)

20. E. Ginting, R. Yulifianti, F.C. Indriani. IOP Conf. Series: Earth Environ. Sci. 456,1 (2020)

21. P.P. Leksrisompong, M.E. Whitson, V.D. Truong, M.A. Drake, J. Sens. Stud. 27, 59 (2012)

22. R. Fadhil, D. Nurba, K. Ikhwanto, Carpathian J. Food Sci.Tech. 9, 2 (2017)

23. A. Odenigbo, J. Rahimi, M. Ngadi, D. Wees, A. Mustafa, P. Seguin, J. Food Process. Technol. 3, 5 (2012)

24. A. Patras, N.P. Brunton, C. O'Donnell, B.K. Tiwari, Trends Food Sci. Technol. 21, 3 (2010)

25. E. Ginting, Retensi antosianin pada beberapa produk olahan ubijalar in Proceeding Seminar Hasil Penelitian Tanaman Aneka Kacang dan Umbi, 21 Desember 2009, Malang, Indonesia (2010)

26. J.A. Woolfe, Sweet potato an untapped food resource (Cambridge University Press, Cambridge, 1992)

27. G.H. Laleh, H. Frydoonfar, R. Heidary, R. Jameei, S. Zare, Pakistan J. Nutr. 5, 1 (2006)

28. T. Jiang, Y. Mao, L. Sui, N. Yang, S. Li, Z. Zhu, C. Wang,S. Yin, J. He, Y. He, Food Chem. 274, 460 (2019)

29. R. Huang, C. Xu, Compr. Rev. Food Sci. Food Saf. 20,1 (2021) 